\title{
"Connecting Mind to Pen, to Eyes, to Face, to Arms and Legs": Toward a Performative and Decolonial Teaching Practice
}

\author{
Miki Flockemann (1D)
}

\begin{abstract}
The push to sustain online learning platforms that have been established in the wake of Covid-19 at South African universities raises a number of concerns. Apart from highlighting the stark and ongoing social inequities in terms of access, the need to ensure that there is still scope in our teaching practice for affective and performative encounters has also been thrown into sharp relief. I draw on two teaching contexts, the one dealing with a literary text, and the other a live performance in order to explore the decolonial potential of affective encounters. In addition to illustrating the complex and unpredictable workings of affect in teaching contexts, I also hope to show how these two incidents offer insight into the interface between sensorial and cognitive knowledge in relation to both literary and performance texts. The aim is to demonstrate how student responses to affective encounters resonate with, rather than directly address, some of the "everyday" processes of decoloniality.
\end{abstract}

Keywords: affect, performance, decoloniality, embodiment, Covid-19, presence

While South African academics have been increasingly urged to adopt blended teaching techniques that involve a greater emphasis on digital learning contexts, two apparently unrelated anecdotes which point to the value of an affective pedagogy prompt some caution here. For instance, the sudden shift to fully online teaching platforms as a result of the lockdown imposed on universities during the Covid-19 pandemic has highlighted the ongoing social chasm between students who have access to digital technology and those who do not. An additional concern is the claim that despite twenty-six years of democracy, there are still broadly two different "classes" of students at our universities: "those who have learnt to enjoy the rights of being a citizen" and those who (the majority of whom are Black students) "have learnt through experience that

Miki Flockemann is Extraordinary Professor in the Department of English at the University of the Western Cape, South Africa. Her primary research interest is the aesthetics of transformation. Her publications include comparative studies of diasporic writings from South Africa, the Americas, and the Caribbean with an emphasis on migrant experiences. She has also published extensively on contemporary South African theater trends with a recent emphasis on the transformative potentiality of affective performance aesthetics. (Email: robmiki@mweb.co.za) 
rights are the domain of privileged others." This ongoing inequity was at the heart of the widespread student protests and university shutdowns in 2015-2016, spearheaded by the \#FeesMustFall student movement, which demanded epistemic access for poor Black students, as well as calling for the decolonization of university institutions. Clearly, issues around access have been catalyzed by both the Covid-19 shutdown and the aftermath of the \#FeesMustFall movement. This is thus urgent given that the swing to digital teaching will no doubt gain momentum even after the lockdown is lifted. The two anecdotes that are recounted here will serve as a point of departure for exploring how student responses to affective encounters resonate with, rather than deliberately address, some of the "everyday" processes of decoloniality. ${ }^{2}$

The first incident occurred thirty-odd years ago when I was just starting my academic career as a lecturer in English literature to a group of rather reluctant firstyear law students at the University of Stellenbosch (US), a historically White university catering for Afrikaans-speaking students at the time. The second occurred in 2015 at the University of the Western Cape (UWC), where I have been working since the mid-1980s. Although UWC is currently a thriving institution only a twenty-minute drive from the scenic university town of Stellenbosch, it was initially a very different kind of campus. In keeping with apartheid-era social engineering of the 1960s, UWC was originally designated for "colored" 3 (or mixed race) students-though currently the demographic makeup is split fairly equally between Black and colored students, while Indian, White, and international students comprise a modest percentage of the overall student body. In this case I was teaching a third-year English elective on theater that has been running for more than a decade and has a strong practice-based component. Students attend several off-campus performances of local productions, develop their own short scripts, and perform these in a final showcase event. Because our campus does not have a drama department, two theater professionals, a playwright and a director, assist with the practical aspect of the course. Although the two anecdotes highlight the complex and unpredictable workings of affective encounters in teaching contexts, I also hope to show how these two incidents offer insight into the interface between sensorial and cognitive knowledge in relation to both literary and performance texts.

It is obviously much easier to generate an affective pedagogy in relation to theater and performance than it is when teaching literary texts, and that is the challenge that needs to be addressed. By way of approaching this challenge, I will draw on student responses to affective encounters in the theater module that illustrate some of the problems that have been identified in relation to the "two classes" paradigm referred to previously. Included here are the kinds of knowledge they encounter, as well as how this is assessed, and the concomitant sense of alienation that surfaces as a result. At the same time, I will also track how their discussions of the effects of affective encounters

1 Jo-Ann Vorster and Lynn Quinn, “The 'Decolonial Turn': What Does It Mean for Academic Staff Development? " Education for Change 21.1 (2017): 31-49, esp. 37.

2 Although decoloniality is associated with the praxis of challenging and delinking from ongoing forms of colonialism, decolonization is associated with the resistance against colonialism; see Walter Mignolo and Catherine E. Walsh, On Decoloniality: Concepts, Analysis, Praxis (Durham, NC: Duke University Press, 2018).

3 Colored remains a contested term in view of its deployment as an apartheid-era racial classification, and though commonly used, it is rejected by those who prefer to identify as Black. 
reveal synergies with what Mignolo refers to as the "decolonial option," which entails delinking from dominant epistemologies through grounded, experiential, and relational learning processes. ${ }^{4}$

But before returning to the anecdotes-the first involving a literary text, the second a performance-it is first necessary to outline in broad strokes what is meant here by an affective encounter. As explained by Massumi, ${ }^{5}$ affect is not a "thing," but occurs when one body (animate or inanimate) impinges upon another; or put another way, when one body affects, or is affected by, another body. Affect thus travels or is transmitted between bodies and is experienced as a "flash" or "moment." Affect is not synonymous with, and indeed precedes, emotion; as Murphie puts it, affect triggers a kind of "proprioception," 6 whereas Wetherell describes affect as "always 'turned on' and 'simmering,' moving along, since action is continually embodied."' Affect is thus synaesthetic, and resonates as intensity, whereas emotions are recognized cognitively. The affect-laden language of the two texts referred to in the anecdotes has a bearing on the semiotic potential of the affective encounter, and the claim that this is a social and communal, rather than only an individual, experience; as emphasized by Manning, affect is collective in the sense that it moves between. ${ }^{8}$ Although the main focus will be on some of the advantages of exposing students to affective encounters in the theater module, I will also consider how a performative teaching strategy could align with (or not) an affective approach to teaching literary texts.

As I was preparing my final lecture on Hardy's The Mayor of Casterbridge on a sweltering Friday afternoon for a group of predominantly conservative and Afrikaansspeaking students who were compelled to take what to them seemed an "irrelevant" English course for their law degree, I mentioned to a colleague that the scene I was focusing on, in which the mayor, Michael Henchard, renounces all forms of mourning rituals on his deathbed, was going to be difficult to communicate to this disaffected group. We even had a laugh about the typically Hardyesque act of tragic self-repudiation evoked by Henchard's litany of negatives when his pencil-written will is discovered pinned to his bed after his death. Henchard's will begins with the request that his own daughter "be not told of my death, or made to grieve on account of me." The list continues:

\footnotetext{
\& that I be not bury'd in consecrated ground.

$\&$ that no sexton be asked to toll the bell.

$\&$ that nobody is wished to see my dead body.

$\&$ that no murners walk behind me at my funeral.

$\&$ that no flours be planted on my grave.

\& that no man remembers me.

To this I put my name. ${ }^{9}$
}

4 Mignolo and Walsh, On Decoloniality, 3.

5 Brian Massumi, Parables for the Virtual: Movement, Affect, Sensation (Durham, NC: Duke University Press, 2002).

6 Andrew Murphie, "Fielding Affect: Some Propositions," Capacious: Journal for Emerging Affect Inquiry 1.3 (2018): 9 .

7 Cornell W. du Toit, "Emotions and the Affective Turn: Towards an Integration of Cognition and Affect in Real Life Experience," HTS Theological Studies 70.1 (2014).

8 Lisa Blackman and Couze Venn, "Affect," Body and Society 16.1 (2010): 7-28, esp. 21.

9 Thomas Hardy, The Mayor of Casterbridge (London: Macmillan Education, 1975), 418. 
Admittedly, I was somewhat dreading the lecture because the previous week, after a class on contemporary South African poetry, one of the students privately informed me in a somewhat patronizing way that I needed to stop "talking politics" in class because he was working for the security police. It was South Africa in the early 1980s after all, and police spies were an occupational hazard, even (or especially) at historically privileged campuses like US. What also rankled was that he clearly thought he was doing me a favor because he assumed that I was too naïve to know what I was doing. So, it was a tense situation. However, when it came to this very passage that I had earlier remarked rather snarkily on, something unanticipated and uncanny happened. In the process of slowly reading the will out aloud, the sonorous incantation, " $\&$ that..." suddenly caught in my throat. I felt unexpectedly and profoundly moved by Henchard's words and sensed that how I felt must have somehow been communicated to the class because the usually restless group suddenly fell completely silent and became engrossed. Afterward, I laughed to family about the fact that I had nearly moved myself to tears in my own lecture. The incident stayed with me for some reason, but only began to make sense when I started work with theories of affect in relation to another incident.

As noted earlier, as part of the practical component of the theater elective at UWC, students participate in excursions to see local performances off-campus in order to introduce them to how a performance makes meaning differently than a literary work does; in addition, the excursions provide a social context to the learning environment and offers opportunities to experiment with newly acquired theater terminology in preparation for their assignments, as well as helping them to acquire some ideas for how to stage their own performances. The aim here was to establish a back-and-forth movement between the experiential or "new" knowledge acquired as a result of the affective encounter with the performance as event and the "taught" knowledge (of theater terms and movements) encountered in the lectures and readings provided. The work we had gone to see was called Trapped, by the innovative Unmute Dance Company-currently South Africa's only "mixed ability" company, which produces work that is powerfully evocative because of the way performers interact with one another to replace missing limbs or absent senses.

The work was performed in an old Methodist church hall, and as we were led into the intimate performance space, the three performers were already in place, each trapped in an installation that we discovered was designed to epitomize their own personal histories of being disabled-as a double amputee, being deaf, and confined to a wheelchair. ${ }^{10}$ The distance between audience and spectators was uncomfortably close; some students sat on the floor in close proximity to the performers, others on makeshift raked seating, and our group made up almost the entire audience. Throughout, the performers remained captive in their respective installations, never communicating with one another, though through lighting, musical cues, and sound effects their narratives shifted in and out of the foreground. The storytelling was thus fragmented, expressed through interactions with objects, movements, or sounds, while the conceptual design of each space was underscored by the performer's individual signature choreography and musical score. For instance, the soundscape of the performer who was a double amputee

10 Zama Sonjika, the double amputee, sadly passed away in 2017; the other performers were Andile Vellum, who is deaf, and Nadine MacKenzie, who is in a wheelchair. 
was an eclectic mix of music and spoken-word declamations (in isiXhosa) as he moved around the confined space with breathtaking agility and speed-by turns cajoling, entreating, defying, or raging at the shoes and boots that dangled tantalizingly above him and surrounded him on the floor, as if mocking his inability to walk.

What was striking about this performance was that directly afterward, even though a Q\&A session had been arranged with the director and cast, no one was able to say what they thought about the work. Myself included. We all felt deeply unsettled, but could not yet articulate this, even though the idea of these excursions is to discuss and grapple with the theater strategies employed in relation to a new aesthetic vocabulary. In this case, however, it took a little time to process the performance's assault on our senses. In discussion afterward it transpired that the inability to formulate a response was not a result of embarrassment or pity for the performers, but rather encountering a sense of one's own "disability." This reaction speaks to one of the commonly identified effects of such affective encounters, described by Paul Gormely as a "body first" reaction. According to Gormley, when encountering a cinematic image, for instance, there is initially a visceral reaction, which is then processed cognitively. Gormley describes this as a "sensory assault," noting that "At the affective moment when the image first assaults us we are temporarily outside "meaning," 11 and that is precisely what happened in relation to the physical stage imagery we were exposed to, and perhaps more importantly, our epiphanic encounter with "what a body can do, rather than what it is." 12 Gormley explains that at the same time, "this moment of disruption also has an impact on the way we make meaning." 13 The suggestion is that before we could "make meaning" cognitively of the affective encounter with the performance, our bodies had responded viscerally and affectively.

The effects of this encounter illustrate a number of other features associated with an affective pedagogy; these include notions of proximity, affinity, intensity, presence, and vulnerability. For instance, several students later spoke about the deeply felt and enduring effects that the performance had on them, and this was also evident from their commentaries in their review assignments. The physical proximity to the performers was no doubt a factor here, in addition to the physically embodied "Otherness" encountered, which was not mediated through familiar class, race, and gender-framed lenses. It was interesting, however, that the dominant feeling was of affinity with-rather than sympathy for-the traumatic personal histories that we had witnessed on stage. This indicated a shift beyond notions of self, to relationality, embodiment, and epiphanies of an affinity with others resulting from the sensory "assault." The notion of intensity, which as explained earlier is associated with an affective "resonance," was partly a consequence of the way attention was focussed because everyone was watching the performance at the same time, without distractions (such as cell phones). Also, for many students this was their first time in a theater (albeit a makeshift one).

11 Gormley in Alyson Campbell, "Adapting Musicology's Use of Affect Theories to Contemporary Theatre-Making: Directing Martin Crimp's Attempts on Her Life," Journal of Adaptation in Film and Performance 5.1 (2011): 1-17, esp. 17.

12 Deleuze and Guattari in Anna Catherine Hickey-Moody and Vicki Crowly, "Disability Matters: Pedagogy, Media and Affect," Discourse: Studies in the Cultural Politics of Education 31.4 (2010): 399-409, esp. 401. Emphasis in original.

13 Campbell, “Adapting Musicology's Use of Affect Theories to Contemporary Theatre-Making," 17. 
The significance of presence, on the other hand, was indicated in the frequency with which they later referred to where they were when they experienced the performance, for example, "as we were sitting and watching," as if recalling the experience again as it was then, in that "moment." This has synergies with how presence has been defined in relation to teaching and learning contexts, namely, as "a state of alert awareness, receptivity, and connectedness to the mental, emotional and physical workings of the individual and the group." ${ }^{14}$ The theater excursions also provide a realignment of lecturer/student dynamics because affective reactions to the performances are unpredictable and the entire group, including the lecturer, is in a position of vulnerability, and this lends itself to a more horizontal than vertical or top-down teaching environment.

The notions of proximity, intensity, affinity, presence, and vulnerability referred to previously also offer scope for delinking from or "disinhabiting" prevailing knowledge. ${ }^{15}$ In turn, the affective semiotic field of live performance events includes physical location, whereas the mise-en-scène is designed to evoke thematic motifs through the placement of material objects that interact with the speech and movement of human actors. All of these elements thus combine to create a multimodal and generative space that is aimed at encouraging audiences to arrive at their own subjective interpretations. ${ }^{16}$ A typical observation on the excursions component is summed up by a comment from a previous cohort of students, which noted that the exposure to live performance changed perceptions about "analyzing according to someone else's hypothesis" because "it not only broadened our horizons but allowed us to write about something we experienced and not just read." Furthermore, this student claimed: "It enabled me to make my own evaluation of a text and substantiate my claim." The environment for such affective encounters is, of course, not hard to accomplish in the context of theater and performance, partly because the intersubjective encounter between spectator and performer is a space where affect travels between bodies. As noted earlier, however, one needs to ask, to what extent might the reaction to stage imagery (such as in Trapped, which utilizes the sensorial impact of sound, lights, and movement) work in terms of the literary material dealt with in the tutorial or lecture context?

In addressing this I return to an article published more than a decade ago on responsive pedagogy. The title, "Body Recognizing Mind," 17 now seems to be the reverse of what I have just referred to previously about the function of affect in performance. Looking more deeply into affect scholarship has made me rethink my own previous assumptions about the way creative engagement might work in our teaching contexts. The article concluded with an example from A. S. Byatt's A Whistling Woman (2002) in order to give substance to the title. What follows is the last paragraph of the article, based on an extract in which Frederika, an English lecturer, reads out a passage from The Great

14 Carol R. Rodgers and Miriam B. Raider-Roth, "Presence in Teaching," Teaching and Learning: Theory and Practice 12.3 (2006): 265-87, esp. 265.

15 Christopher Stroud, "Linguistic Citizenship" in The Multilingual Citizen: Towards a Politics of Language for Agency and Change, eds. Lisa Lim, Christopher Stroud, and Lionel Wee (Bristol: Multilingual Matters, 2018), 5.

16 Keir Elam, The Semiotics of Theatre and Drama (London: Routledge, 2003).

17 Miki Flockemann, "Body Recognizing Mind'? Negotiating Knowledge through Performance," South African Journal for Language Teaching 41.2 (2007): 34-45. 
Gatsby describing Gatsby's disintegration, a passage that she had read aloud to her classes many times before:

\begin{abstract}
But as she read it out, she caught the full force of the achieved simplicity of every word in that perfectly created paragraph. She felt something she had always supposed was mythical, the fine hairs on the back of her neck rising and pricking in a primitive response to civilized perfection, body recognizing mind. ${ }^{18}$
\end{abstract}

Later she says that it is as if, for the first time, she has "really seen" how good the paragraph is. This becomes a defining moment for her, where the physical reaction, the "pricking" hairs, indicate her "really reading" something that "she believed she "knew." 19 Here learning, understanding, and knowledge are experiential in the sense that this is physically experienced in the pricking hairs at the nape of her neck, yet, the physical reaction is a response to a cognitive, intellectual stimulus, mediated through a sophisticated understanding of culturally informed (literary) codes. This example demonstrates the complex relationship between formal academic knowledge and experiential learning, or between sensorial and cognitive knowledge. At the same time, it points to the value of an integrated and fluid exchange between "taught" knowledge (in terms of the theater elective these would be theater conventions) and individual experience or practice (through excursions and through creating students' own performances). The moments of "recognition" that are experienced affectively can thus result in recognition of already acquired knowledge (similar to Byatt's "body recognizing mind"). The act of critical reading using the academic tools of analysis are then translated into a felt experience of "really seeing/knowing," as if the ideas were freshly arrived at (as in, "experienced, and not just read").

In hindsight, two issues emerge from this example. First, it is striking to note the synergies between the way Byatt describes the lecturer's reaction to reading aloud the extract from The Great Gatsby, and my own reaction to reading aloud Henchard's will all those years ago. Although the lecturer's embodied reactions manifested in the pricking of hairs in the nape of her neck, mine became evident in the apparently involuntary constriction in my throat when voicing Henchard's words. In addition, I had the similar sensation of unexpectedly "really" encountering Henchard's words, as if for the first time. Perhaps a contributing factor here was the general sense of unease I had about the lecture generally, but on voicing his words, the existential anguish of Henhard's selfrepudiation suddenly swept away what seemed like other petty anxieties, and I was caught up in the drama of his psychic pain, communicated in the simple, but unbearably poignant cadences of Henchard's own idiosyncratic sentence tones, something Hardy is a master at capturing. From this it appears that there is no reason why a literary text should not generate a sensory "assault." However, what has been referred to as the "affective atmosphere" of the lecture room at the time was undoubtedly an additional contributing factor. Brennan describes an affective atmosphere as being "affectively charged." 20 by processes that come "via interaction with other people and an

18 A. S. Byatt, Whistling Woman (London: Chatto and Windus, 2002), 269.

19 A. S. Byatt, Whistling Woman, 270

20 Teresa Brennan, The Transmission of Affect (Ithaca: Cornell University Press, 2004), 1 
environment"; ${ }^{21}$ this points again to the social and collective aspect of the affective encounter, as manifested in the sudden "presence" and attentiveness of the students in response to my "being affected" by the extract I was reading to them.

The second issue is that given the discussion on the relationship between cognitive and sensorial knowledges and the body-mind nexus, should the title not have been "Mind Recognizing Body?" After all, as noted earlier, affect is an unstructured, preconscious, nonsignifying system that affect theorists claim is distinct from but implicit in emotion and cognition. Or put another way, affect is that which is sensed (or resonates) as intensity in the limbic system, and at its most intense it is expressed as emotion in the neocortex. In the case of the extract from The Great Gatsby, however, it is the aesthetic object, the text, and its codes that are accessed cognitively that trigger an affective (bodily) response. But then again, one could ask, is it not the act of performing the text, reading it out loud, involving voice, cadence, breath, as well as bodily posture that generates the affective atmosphere that elicits the concomitant prickling hairs or constricted throat response? Or is this just a circular argument, just as the brain's limbic system and the neocortex feed messages backward and forward? Furthermore, how might one achieve something similar using the academic tools of analysis so that students might feel as if ideas are "freshly arrived at"?

Maybe one way to address this is to work backward, by identifying those affectsaturated aspects drawn from the student responses to the theater course that align with a decolonial pedagogy, and then speculate whether these responses might be transferred to their encounters with literary texts. For instance, annual surveys of student responses have consistently highlighted a number of interrelated areas. ${ }^{22}$ These include the students' "voice," not only in written exercises (including their own script development processes as well as formal assignments), but also in terms of being heard and listened to in tutorial discussions. Then there is their sense of what can be described as a rhizomic rather than hierarchical learning process. In addition, there is an emphasis on an awareness of their own embodiment and location, and finally, students refer to epiphanies of empathy and a sense of affinity with others. Of additional interest here is how their responses align with or indirectly speak to some of the very issues a decolonial pedagogy attempts to address.

In terms of "voice," for example, it became evident from a number of comments that many students feel alienated and silenced in academic contexts, so that being able to express themselves creatively, or in response to "something we experienced and not just read," resulted in a freeing up of voice as suggested by "we were writing without being shunned," or, as another put it, she or he felt "free to be you and not afraid of giving the wrong answer." In addition, "The course allows us to breathe and not feel like everything we learn is forgotten." Particularly arresting here is the word shunned, which suggests not just being ignored, but a feeling of being deliberately dismissed or rejected. Coupled with the reference to the "fear" of giving wrong answers, this serves as a telling indictment of the way some students experience their learning environment.

21 Brennan, The Transmission of Affect, 3.

22 I explore this in more detail in "Affect, Performance and Language: Implications for an Embodied and Interventionist Pedagogy," in Languages and Literacies in Higher Education, Reclaiming Voices from the South, eds. Zannie Bock and Christopher Stroud (London: Bloomsbury Press, 2020 [forthcoming]). 
Creating an atmosphere where students feel they are heard and listened to, irrespective of which of the "classes" they fall into, is thus crucial in generating a sense of belonging. It is ironic that despite Achille Mbembe's injunction: "This is my home. I am not an outsider here. I do not have to beg or apologise to be here. I belong here," 23 many Black students are generally still positioned as and also sense themselves to be on the margins of university life. In his address to a group of students from UWC and US participating in a collaborative linguistics project on local language histories in 2018, visiting Brazilian scholar Lynn Mario T. Menezes de Souza invoked a central tenet of Freire's decolonial pedagogy, namely, the "locus of enunciation" ${ }^{24}$ as a primary consideration to be taken into account for the students' project. Although this has become a central focus for resisting hegemonic epistemologies and enacting solidarities across diasporic communities (especially South American, Asian, and African diasporas), Mbembe's comment, "I belong here," suggests that this could have a rather different inflection for those in the global south-especially in South Africa with its dual legacies of colonialism and apartheid, so that a starting point of delinking from the legacies of these master narratives is to claim the right to belong locally, as a citizen. ${ }^{25}$ More pertinent to this discussion on the decolonial potential of affective teaching methodologies, however, is de Souza's claim that the reason we need to bring the space from which we speak into account in our teaching and learning endeavors is that, in turn, this "brings into account something which has been eliminated from academic discourse, which is the body." 26 One of the reasons for this elimination is the idea that "bodies are what bothers our thinking." ${ }^{27}$ What we have seen here, however, is the reverse, namely, that instead of limiting or "bothering" thinking, the experience of embodiment in effect "frees up" thinking as a result of the interface between sensorial and cognitive knowledges. De Souza also stresses the importance of creativity and the imagination as key features to decolonial pedagogy in the sense of breaking out of "established learning and looking for something new" ${ }^{28}$ (or in the case of literary texts, something "newly realized"). It was clear from the theater student responses that their own creative involvement was crucial to this process, especially the free-writing exercises in preparation for writing their monologues. One aspect of the comments about a more democratic (or rhizomic in the sense that discussion can go in a number of directions) learning experience refers to the open-ended tutorial conversations that took place after each theater excursion. Because we (students and lecturer) had seen the same performance, there was a sense of mutuality, and students were encouraged to first comment on what they liked (if anything) or to identify a "moment" that stayed with them. After everyone had spoken, we discussed more analytical aspects of the aesthetic strategies employed and

23 Achille Mbembe in Vorster and Quinn, “The Decolonial Turn," 44.

24 Lynn Mario T. Menezes De Souza, “Decolonial Pedagogies, Multilingualism and Literacies," Multilingual Margins: A Journal of Multilingualism from the Periphery, 6.1 (2019): 9-14, esp. 12

25 In light of prevailing discourses of South African exceptionalism and claims to autochthonous belonging, there is need for caution here because such discourses of local belonging have been used to exclude other fellow Africans, as seen in the ongoing manifestations of xenophobia targeting Africans from elsewhere on the continent living among local, poor Black communities.

26 De Souza, "Decolonial Pedagogies, Multilingualism and Literacies," 12.

27 De Souza, "Decolonial Pedagogies, Multilingualism and Literacies," 12.

28 De Souza, "Decolonial Pedagogies, Multilingualism and Literacies," 11. 
how effective these were (or not). What was useful here is that everyone felt able to respond; it was not about right or wrong interpretations, but rather the emphasis was on how meaning was made in performance. In this atmosphere ideas could be tested and one could change one's mind or acknowledge another person's point of view, even if one did not share it.

The space or place from which each person spoke was implicit in this type of discussion. In addition, the link between embodiment and location was often described as a sensory reaction to an affective experience, which in turn triggered a cognitive shift, often expressed as an epiphany of sorts. This is captured in one student's almost lyrical description of translating a script into a performance with the guidance of the showcase director, who "connected my mind to my pen to my eyes to my face to my arms and legs.... I felt a unity among my script, my body and my voice. I was a living story... I harnessed the stories bound to my skin." The comment was made by an international student, who was also referring to his own recognition of his embodied and historical "difference" in relation to others in the class. Another older student who had lived through the era of resistance against apartheid remarked on the effects that some of the most intense performances had on her, saying that they "bring you back to your body.... It brings back your human element. It reminds you that you are not a robot but a body with a faculty of reasoning." This again foregrounds the body-mind nexus in that the affect-saturated performance space offers fertile ground for epiphanies such as those suggested by this student, who sees her own rationality as being integral to her embodied humanity, as if for the first time.

At one level it would appear that the responses quoted here are bounded by an interplay between individuality and universality, rather than the more reflexive delinking impetus of a decolonial option as advanced by Mignolo. ${ }^{29}$ It is certainly the case that there is an absence here of a critical notion of decolonial liberation of themselves and others like them; yet, as noted earlier, these affective and embodied ways of "knowing" referred to in the students' responses are inevitably relational and social, even if not recognized as such at the time. It could also be argued that the statement "it reminds you that you are not a robot" is a metaphoric recognition of how thinking processes seem to be "controlled" or even "imprinted" by an imperial colonizing "machine" rather than emerging from within her own embodied experiences. On the other hand, the student who referred to the "stories harnessed to my skin" was alluding to his inherited complicity in what Mignolo recalls as the "colonial wound." ${ }^{0}$

Given that a typical feature of contemporary South African theater involves a constant dialogue between "the written word, the spoken word, and the transformative material body," ${ }^{31}$ how might one generate similar affective encounters in relation to responding to literary texts? This is certainly readily achievable in courses such as creative writing and film, which are already commonly offered in tandem with the core literary courses. There is, of course, nothing new about using comparative approaches or

29 Rubén Gaztambide-Fernándes, “Decolonial Options and Artistic/AestheSic Entanglements”: An Interview with Walter Mignolo," Decolonization: Indigeneity Education and Society 3.1 (2014): 196-212.

30 Gaztambide-Fernándes, "Decolonial Options and Artistic/AestheSic Entanglements," 201.

31 Mark Fleishman, "Physical Images in the South African Theatre," South African Theatre Journal 11.1-2 (1997): 199-214, esp. 200. 
including multimodal and affect-laden media (including visual images, paintings, music, and videography) to enhance readings of literary texts. In keeping with a decolonial approach, however, the challenge is to provide scope for affective engagement with literary texts in ways that also establish a dialogue with the "difference" (and hence "difficulty") of some of the texts they are engaging with.

One possible approach might be to include the notion of translation, which as de Souza points out, needs to be understood in terms of decolonial theory as "a recognition of difference." 32 This can take the form of a creative response or a free-writing exercise as part of the interpretive process, but approached in such a way that it foregrounds the place from which one speaks (in terms of embodiment and location). De Souza further explains: "Translation is recognition of incompleteness" ${ }^{33}$ and argues that this recognition of difference and incompleteness is of critical importance because "we have to understand that not understanding is part of understanding," ${ }^{34}$ Although this might sound cryptic, the idea is that when students share their embodied and sensory "translations" of the literary text (or aspects of it), which can take any number of writerly or other aesthetic modes, it provides scope for a free-flow of ideas and might render the "difference" of the text much more directly accessible when they return to the literary text again using the conventional modes of analysis. Another strategy that might sound counterintuitive at first is to focus on the very specificities that appear to render the texts encountered "different/difficult" in order to identify potential points of affinity, and work from those, because as noted earlier a sense of affinity is generated by a transmission of affect. The aim here would be to move away from a focus on "difference" to points of connection, within a framework where "specificity provides the ground for commonality without sameness."

As suggested by the examples described previously, it is by no means impossible to encounter a felt experience of "really seeing/knowing," as if meanings were freshly arrived at, while engaging with a literary text. However, it remains undoubtedly more difficult to achieve in comparison with performance texts, which by their very nature are more conducive to affective encounters. For instance, the ability to affect and be affected happens in real time in the virtual contact zone of the "affective atmosphere" of the performance space. An additional constraint in terms of dealing with literary texts is that, unlike a lecture venue, the performance arena is also a briefly communal (even ritual) space, where the spectating body is acted upon by the performing body. It is also clear that given the efforts to establish stronger digital learning platforms to address social distancing regulations in the wake of Covid-19, blended or online teaching will inevitably be strongly encouraged, and this can result in further alienation for many students in terms of responding to literary texts. For these reasons it seems especially important to ensure that there is still scope in our teaching practice for affective and performative encounters and their concomitant decolonizing potential. At the very least, we should provide opportunities to translate, to "breathe" and respond imaginatively, while also reminding ourselves to be aware of the locations from which we speak.

32 De Souza, "Decolonial Pedagogies, Multilingualism and Literacies," 14. Emphasis in original.

33 De Souza, "Decolonial Pedagogies, Multilingualism and Literacies," 14. Emphasis in original.

34 De Souza, "Decolonial Pedagogies, Multilingualism and Literacies," 14.

35 Phelan in Jodie Dean, "Feminist Solidarity, Reflective Solidarity: Theorizing Connections After Identity Politics," Women and Politics 18.4 (1997): 1-26. 